\title{
CERAMIC PROPERTIES OF PUGU KAOLIN CLAYS. PART 2: EFFECT OF PHASE COMPOSITION ON FLEXURAL STRENGTH
}

\author{
Leonard D. Akwilapo $^{1 *}$ and Kjell Wiik ${ }^{2}$ \\ ${ }^{1}$ Department of Chemistry, University of Dar es Salaam, P.O. Box 35061, Dar es Salaam, \\ Tanzania \\ ${ }^{2}$ Department of Chemistry, Norwegian University of Science and Technology, N-7491, \\ Trondheim, Norway
}

(Received March 17, 2003; revised September 22, 2003)

\begin{abstract}
Whiteware compositions prepared using Pugu kaolin and industrial grade quartz and feldspar were studied with respect to varying sintering temperatures. The strength developed was correlated to mullite $\left(3 \mathrm{Al}_{2} \mathrm{O}_{3} \cdot 2 \mathrm{SiO}_{2}\right)$ content and the microstructure. It was observed that within the vitrification temperature range, the strength mainly depended on the mullite content and the bulk density. Above the vitrification temperature range the deterioration of the strength is due to the coarsening of mullite needles and bloating.
\end{abstract}

KEY WORDS: Ceremic properties, Kaolin clay, Flexural strength, Mullitisation, Bulk density, Modulus of Rupture, Microstructure

\section{INTRODUCTION}

Porcelain is one of the most researched materials in the whole family of ceramics. Researchers working in this field have established factors controlling the various properties of porcelain, and this has contributed significantly to property improvement. Porcelain is prepared from a mixture of three major minerals; quartz, feldspar and kaolin clay (also called china clay). The proportions of these components influence both the phase compositions of the fired body and their mechanical and physical properties [1].

Up to the present, several theoretical considerations on the factors affecting the strength of porcelains have been proposed. Two theories are of interest in this contribution. The first one is related to the interlocking of the feltlike mullite $\left(3 \mathrm{Al}_{2} \mathrm{O}_{3} \cdot 2 \mathrm{SiO}_{2}\right)$ needles [2] while the other is based on the internal stress theory [3].

In the first theory the amount and morphology of mullite needles are parameters that affect the strength of porcelain materials. It has been shown that with increasing mullite content the strength increases, but when fired at high temperatures for long times the mullite coarsens, and as a consequence, the strength decreases $[2,4]$. Studies on the vitrification and fired properties of an electrical porcelain body [5] have shown that with increasing peak firing temperature the formation of mullite increases, and the maximum mullite formation is reached at around $1230{ }^{\circ} \mathrm{C}$. Above this temperature the mullite crystals increases in size only at the expense of small needles; thus the quantity remains constant. Simultaneous with mullite formation, the amount of quartz also decreases with increased dissolution at higher temperatures.

In the later theory, the strength was assumed to be affected by residual stresses generated during cooling due to the differences in the thermal expansion of the glass matrix and residual crystalline particles (quartz, cristobalite or alumina). As a particular example, electrical porcelains were recognised to show relatively high strength as cristobalite was produced from quartz or kaolin [6]. It follows, then, that the grain size of quartz is an important factor as far as

*Corresponding author. E-mail: akwilapo@chem.udsm.ac.tz 
strength development is concerned, since both smaller and larger grains give lower strength. This is explained by the extensive dissolution of the small quartz grains and crack propagation around the large grains in the body matrix [7].

The aim of the present work was to evaluate the suitability of Pugu kaolin clay as a raw material in the production of porcelain materials. In Part I of this series [8] a linkage between porosity and the developed strength was reported. In the present contribution focus is on the development of the mullite phase, which as some authors have shown, it is responsible for strength development in the material.

\section{EXPERIMENTAL}

\section{Raw materials}

The raw materials selected were kaolin clays from Pugu deposit in Tanzania, Norfloat potash feldspar NGP 200 and Norfloat quartz NGQ 250. The chemical composition of feldspar and quartz were supplied by the manufacturer while that of Pugu kaolin clay was determined by Phillips PW 1480 XRF spectrometer. Standard procedures for the quantitative determination of constituents of whiteware raw materials were followed [9]. Table 1 depicts the chemical composition of the raw materials. The particle size distribution of Pugu kaolin clay, as determined by Coulter LS 230 Particle Size Analyser and those of feldspar and quartz, as supplied by the manufacturer are shown in Table 2.

Table 1. Chemical composition (mass \%) of the raw materials.

\begin{tabular}{|l|l|l|l|l|l|l|l|l|l|}
\hline Component & $\mathrm{SiO}_{2}$ & $\mathrm{Al}_{2} \mathrm{O}_{3}$ & $\mathrm{Fe}_{2} \mathrm{O}_{3}$ & $\mathrm{TiO}_{2}$ & $\mathrm{CaO}$ & $\mathrm{MgO}$ & $\mathrm{K}_{2} \mathrm{O}$ & $\mathrm{Na}_{2} \mathrm{O}$ & $\mathrm{LOI}$ \\
\hline Pugu kaolin & 46 & 36 & 1.43 & 0.87 & 0.24 & 0.62 & 0.31 & 0.19 & 10.5 \\
\hline Feldspar ( NGP 200) & 66 & 18.5 & 0.07 & - & 0.4 & - & 11.80 & 2.90 & 0.15 \\
\hline Quartz ( NGQ 250 ) & 99.6 & 0.25 & 0.01 & - & - & - & - & - & 0.10 \\
\hline
\end{tabular}

Table 2. Particle size distribution (mass \%) of the raw materials.

\begin{tabular}{|lllll|}
\hline Component & $<74 \mu \mathrm{m}$ & $<44 \mu \mathrm{m}$ & $<20 \mu \mathrm{m}$ & $<10 \mu \mathrm{m}$ \\
\hline Feldspar ( NGP 200) & $98-99$ & $88-90$ & $58-62$ & $38-42$ \\
\hline Quartz ( NGQ 250 ) & $95-99$ & $92-94$ & $64-68$ & $36-40$ \\
\hline Pugu kaolin clay & 95 & 91 & 72 & 59 \\
\hline
\end{tabular}

\section{Choice of compositions}

Batch compositions were chosen to represent the ordinary products in the whiteware industry [10]. These are the standard porcelain, vitreous whiteware (sanitary), electrical porcelain and hard porcelains (Table 3). All the batch compositions are located in the mullite field section in the silica-alumina-alkali phase equilibrium diagram (Figure 1). Emphasising the fact that mullite is the essential component in controlling the properties of whiteware materials.

Table 3. Compositions (mass \%) of the raw porcelain mixes prepared.

\begin{tabular}{|l|l|l|l|l|}
\hline Abbreviation & Body type & Pugu kaolin & Feldspar NGP 200 & Quartz NGQ 250 \\
\hline P1 & Electrical insulation ware & 40 & 30 & 30 \\
\hline P2 & Standard porcelain composition & 50 & 25 & 25 \\
\hline P3 & Vitreous sanitary ware & 50 & 30 & 20 \\
\hline P4 & Hotel China & 40 & 20 & 40 \\
\hline
\end{tabular}

Bull. Chem. Soc. Ethiop. 2004, 18(1) 


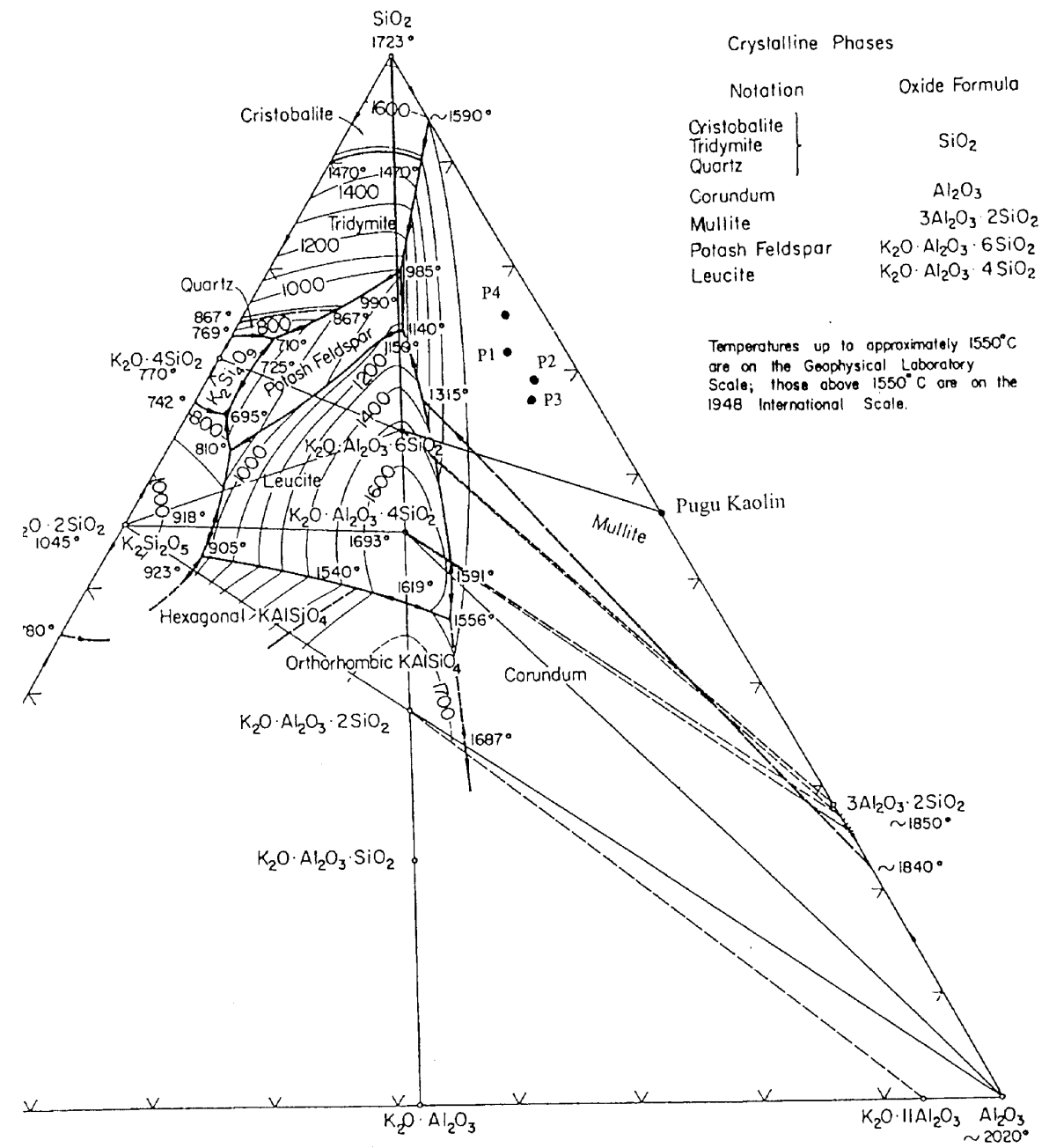

Figure 1. The studied compositions shown on the silica-alumina-alkali phase equilibrium diagram (extracted from Levin et al. [11]).

\section{Sample preparation}

The body formulations were mixed with a calculated volume of water so that the resulting slip contains $28 \%$ water. Dolaflux $0.05 \%$ by volume was added to act as a deflocculant. The mixtures were ball milled for 24 hours to allow intimate mixing so as to increase the probability of obtaining a homogeneous body, which is known to enhance the rate of reaction at higher temperatures and hence the mullitisation processes [12]. It is supposed that fired homogeneity is 
obtained if the number of contacts between particles of different mineralogical species is large and thus minimising the diffusion distances between the particles.

The slips were casted into bars of $17 \mathrm{~cm} \times 1.5 \mathrm{~cm} \times 0.5 \mathrm{~cm}$ in plaster of Paris moulds and then dried in air for 24 hours before drying in a laboratory oven at $110 \pm 10{ }^{\circ} \mathrm{C}$ for 48 hours. The prolonged drying was considered suitable for the purpose of avoiding surface cracking on the test pieces, which would have occurred during firing as a result of excessive surface drying. This phenomenon is known to occur as the surface becomes exceedingly dry compared to the wet interior, and in most cases results in the development of surface stresses that culminate into crack formation. The bars were fired at the rate of $300{ }^{\circ} \mathrm{C}$ per hour to the predetermined soak temperature and held for 8 hours.

\section{Modulus of rupture}

All the modulus of rupture (MOR) results were obtained in a three-point bending test using Digimaxx C-20 instrument. The distance between the bearing edges was set at $70 \mathrm{~mm}$ and the load applied uniformly at a right angle to the rectangular bars at the rate of $0.05 \mathrm{kN} / \mathrm{s}$ until failure occurred. The MOR was calculated from the formula:

$M=\frac{3 P L}{2 b d^{2}}$

where $\mathrm{M}=$ modulus of rupture $(\mathrm{MPa}), \mathrm{P}=$ load at rupture $(\mathrm{N}), \mathrm{L}=$ distance between supports $(\mathrm{mm}), \mathrm{b}=$ width of the specimen $(\mathrm{mm}), \mathrm{d}=$ thickness of the specimen $(\mathrm{mm})$.

\section{Phase quantification}

The amounts of the crystalline phases after firing were determined by XRD using $\mathrm{CaF}_{2}$ as the internal standard $[13,14]$. All the XRD work was performed using a Phillips PW 1050 goniometer with a PW 1710 microprocessor based controller and measuring system. The scan parameters for all runs are indicated below:

$\mathrm{X}$-ray source $\mathrm{Cu}-\mathrm{K} \alpha$

Wavelength $(\AA) \quad 1.5418$

Counting time (s) 1

Counting interval $(2 \theta) 0.01$

Scanning interval $(2 \theta) 15-38$

Peaks chosen for the determination are indicated in Table 4. The selected peaks are distinct, highly resolvable and have high intensities to facilitate the detection of low concentrations of the analytes (Figure 2).

Table 4. Peaks used for the determination of the phases.

\begin{tabular}{|l|l|l|l|l|}
\hline Phase & $\begin{array}{l}2 \theta \text { angle } \\
\text { (degrees })\end{array}$ & $\begin{array}{l}\text { d-spacing } \\
(\AA)\end{array}$ & $\begin{array}{l}\mathrm{I} / \mathrm{I}_{\mathrm{o}} \\
(\%)\end{array}$ & hkl values \\
\hline Mullite & 32.22 & 2.694 & 40 & 220 \\
\hline Cristobalite & 21.985 & 4.0397 & 100 & 101 \\
\hline Quartz & 26.65 & 3.342 & 100 & 101 \\
\hline Fluorite $\left(\mathrm{CaF}_{2}\right)$ & 28.267 & 3.1546 & 92 & 111 \\
\hline
\end{tabular}

Bull. Chem. Soc. Ethiop. 2004, 18(1) 


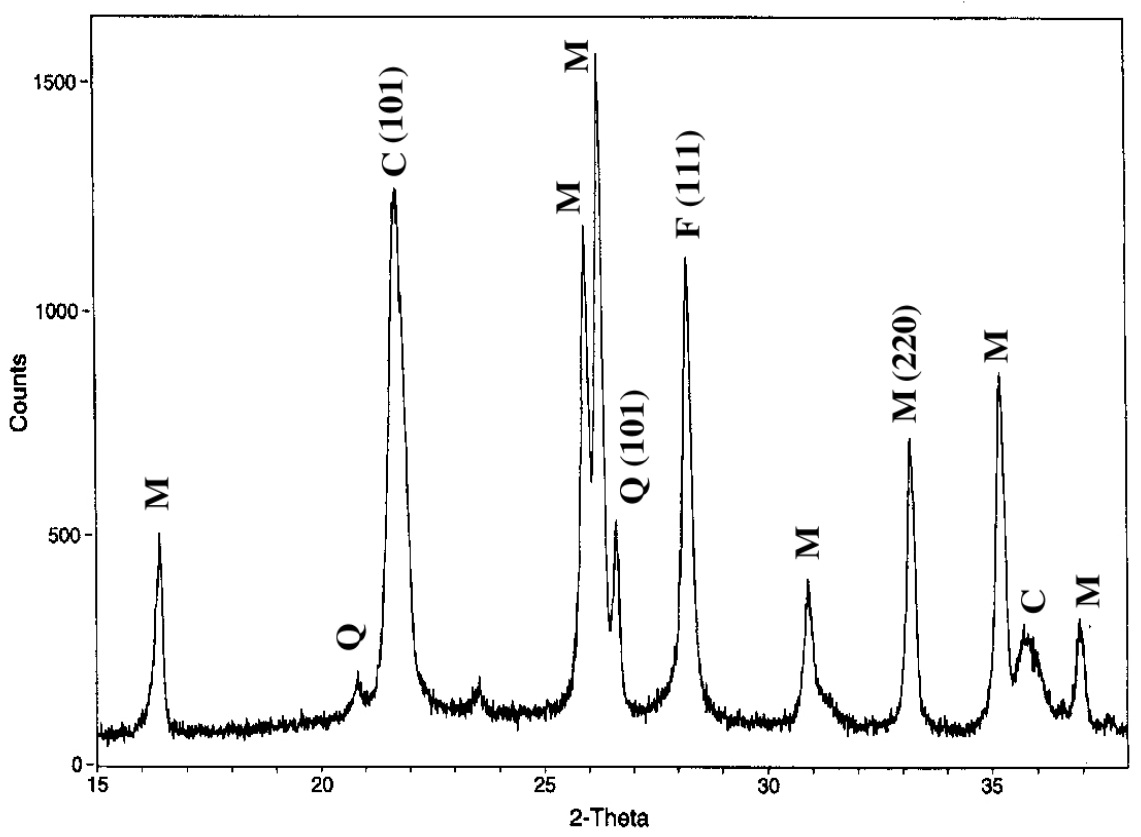

Figure 2. XRD profile of a conventional porcelain body recorded between 2-theta values of $15^{\circ}$ and $36^{\circ}$. The abbreviations $\mathrm{M}, \mathrm{Q}, \mathrm{C}$ and $\mathrm{F}$ refer to mullite, quartz, cristobalite and fluorite peaks, respectively.

\section{Microstructure}

The microstructure was studied using a scanning electron microscope (SEM) Model Carl Zeiss DSM 940. Before scanning samples were etched in $40 \% \mathrm{HF}$ acid to remove the glass phase.

\section{RESULTS AND DISCUSSION}

\section{Phase composition}

Fired bodies were considered to consist of quartz, mullite and cristobalite, as crystalline phases and glass as an amorphous phase. The glass content is obtained by difference, as the total mass content should make up to $100 \%$. Alumina was not considered in the determination, as there is no evidence of its formation either from kaolin or feldspar. The XRD patterns of all batch compositions were checked for the presence of corundum peaks (e.g. the 012 reflection of corundum at $d=3.48 \AA$ ) and it was concluded that it was absent in all compositions. The phase diagram in Figure 1, which shows alumina is not a coexistent phase at equilibrium for the compositions considered, also confirms this fact. The phase compositions of the fired porcelain samples investigated in this work are shown in Figure 3. 


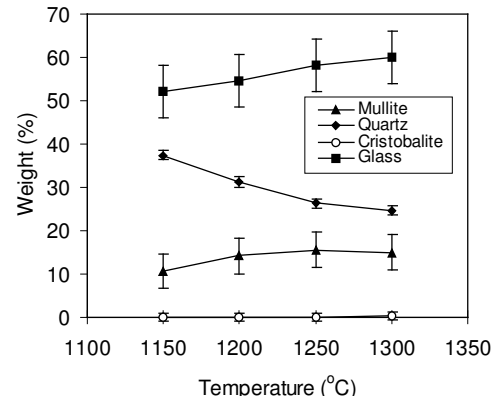

(a)

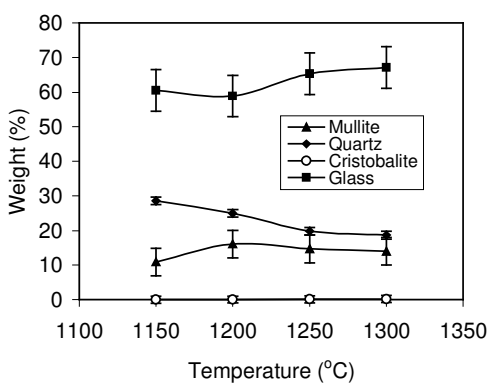

(c) (b)
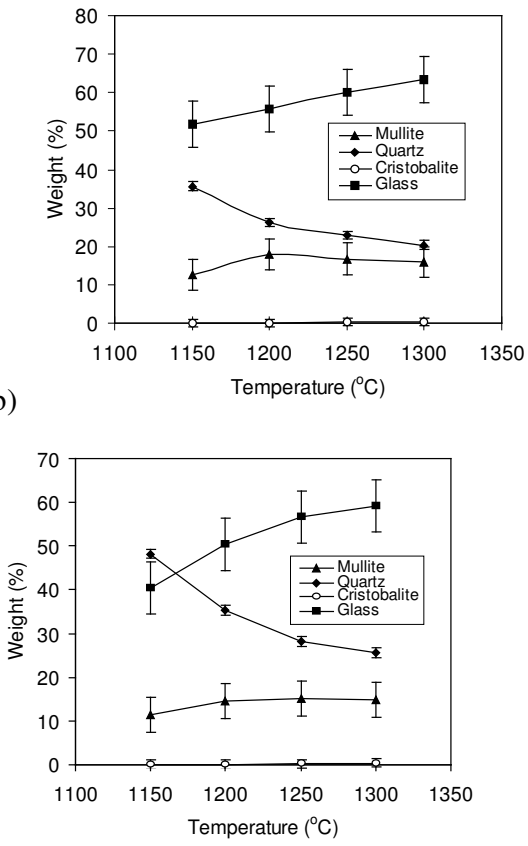

Figure 3. Phase composition of porcelain samples (a) P1 (b) P2 (c) P3 and (d) P4 held for 8 hours at the peak firing temperature (heating rate $300{ }^{\circ} \mathrm{C} /$ hour).

In Table 5 the equilibrium composition of the porcelain samples after firing at different temperatures are displayed along with the experimentally determined values. The equilibrium compositions are calculated from the phase diagram in Figure 1. It is observed that the measured quantities are not in agreement with the equilibrium values. This discrepancy is associated with the kinetics of the reactions taking place. Reactions in this system involve solid particles, and some of them (like quartz) require higher temperatures or longer residence times to react. In this case the reactions do not reach equilibrium.

Mullite has been observed and quantified in all samples fired at and above $1150{ }^{\circ} \mathrm{C}$. The relevant curves give the total mullite contents present in the samples since the method used does not distinguish between primary and secondary mullite. The general observation for all samples is the increase of mullite content with the soak temperature up to a maximum point followed by a slight decrease as the soak temperature is increased further. The maximum mullite content is obtained between 1200 and $1250{ }^{\circ} \mathrm{C}$. These results will suggest that the dissolution of mullite begin to occur at $1200{ }^{\circ} \mathrm{C}$ as there appear to be no significant increase in the mullite content above that temperature. Theoretically the mullite content would be expected to rise with the rise of temperature until all the potential reactants have been consumed. However this is not the case, as smaller primary mullite grains will dissolve to build large secondary mullite needles [15]. 
Table 5. Equilibrium and experimental phase content of porcelain $\mathrm{P}$ samples after firing at diffrent temperatures for 8 hours.

\begin{tabular}{|c|c|c|c|c|c|c|c|}
\hline \multirow[t]{2}{*}{ Sample } & \multirow{2}{*}{$\begin{array}{l}\text { Firing } \\
\text { temperature }\end{array}$} & \multicolumn{2}{|c|}{ Mullite (\%) } & \multicolumn{2}{|c|}{ Silica (\%) } & \multicolumn{2}{|c|}{ Glass (\%) } \\
\hline & & Equi. & Exp. & Equi. & Exp. & Equi. & Exp. \\
\hline \multirow{4}{*}{ P1 } & 1150 & 22 & 11 & 16 & 37 & 62 & 52 \\
\hline & 1200 & 21 & 14 & 13 & 31 & 66 & 55 \\
\hline & 1250 & 21 & 16 & 8 & 26 & 71 & 58 \\
\hline & 1300 & 20 & 15 & 3 & 25 & 77 & 60 \\
\hline \multirow{4}{*}{ P2 } & 1150 & 28 & 13 & 18 & 36 & 54 & 52 \\
\hline & 1200 & 28 & 18 & 15 & 26 & 57 & 56 \\
\hline & 1250 & 27 & 17 & 10 & 23 & 63 & 60 \\
\hline & 1300 & 26 & 16 & 5 & 21 & 69 & 64 \\
\hline \multirow{4}{*}{ P3 } & 1150 & 28 & 11 & 5 & 29 & 67 & 61 \\
\hline & 1200 & 28 & 16 & 1 & 25 & 71 & $\begin{array}{l}59 \\
\end{array}$ \\
\hline & 1250 & 27 & 15 & 0 & 20 & 73 & 65 \\
\hline & 1300 & 26 & 14 & 0 & 19 & 74 & 67 \\
\hline \multirow{4}{*}{ P4 } & 1150 & 24 & 10 & 40 & 48 & 36 & 41 \\
\hline & 1200 & 24 & 14 & 34 & 35 & 42 & 50 \\
\hline & 1250 & 23 & 16 & 32 & 28 & 45 & 57 \\
\hline & 1300 & 22 & 15 & 30 & 26 & 48 & 59 \\
\hline
\end{tabular}

Equi. $=$ Equilibrium. Exp. $=$ Experimental.

\section{Microstructure}

The closeness of the soak temperatures has made it difficult to obtain a progressive change in the microstructure as the temperature is increased. Thus although there should be a strong relationship between the microstructure and the mechanical properties, microstructural differences for samples fired at such close hold temperatures are observed to be very small. The small differences are apparently due to the slow reaction kinetics of these solid state reactions. The microstructure of the samples fired at 1200 and $1250{ }^{\circ} \mathrm{C}$ are depicted in Figure 4. From the two micrographs it is evident that the quartz particles in contact with the feldspar melt dissolve very slowly leaving a large amount of residual quartz grains after firing. This has an adverse effect on the strength development since large spaces around grains would be sources of crack propagation [7].

Also evident from the SEM pictures (Figure 4) is the presence of mullite needles. Two types of mullite are formed in triaxial porcelain bodies. Primary mullite, which is in the form of scales, forming mainly within the clays; and secondary mullite, usually in the form of needles, precipitating at clay-glass interface inside feldspathetic melts [15]. Secondary mullite crystals are anisotropic that often show a pronounced needle shape structure growing preferentially along the c-axis [16]. But since the distribution of the body components in this system is random, no preferred orientation of the needle should occur during their formation. As a result, the needle-like crystals grow in all directions, culminating into a three-dimensional network (Figure 4). Such a network of intertwined needles reinforces the glassy matrix, and thus strengthens the material. 
(a)

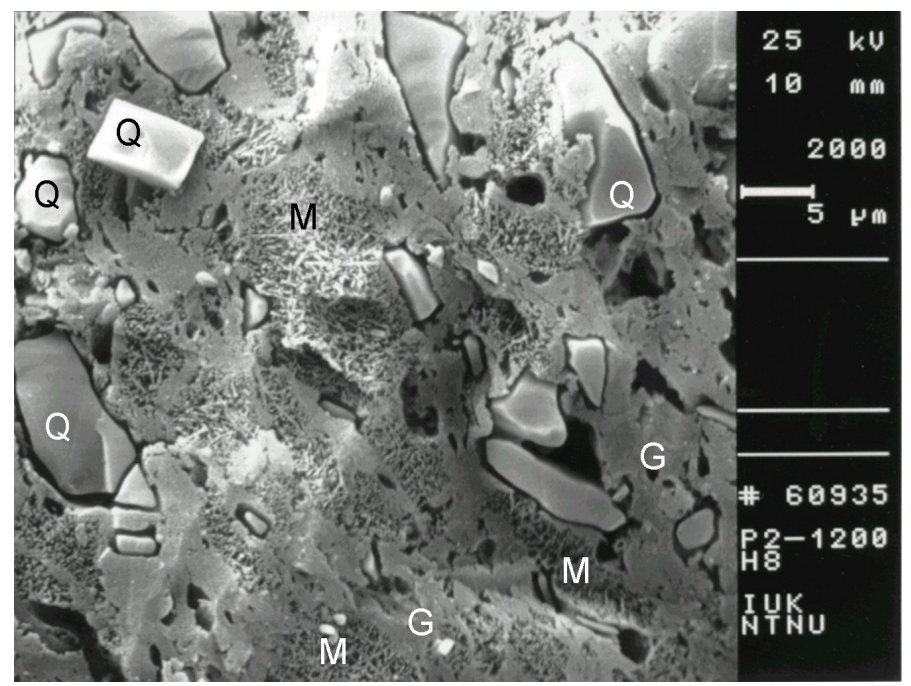

(b)

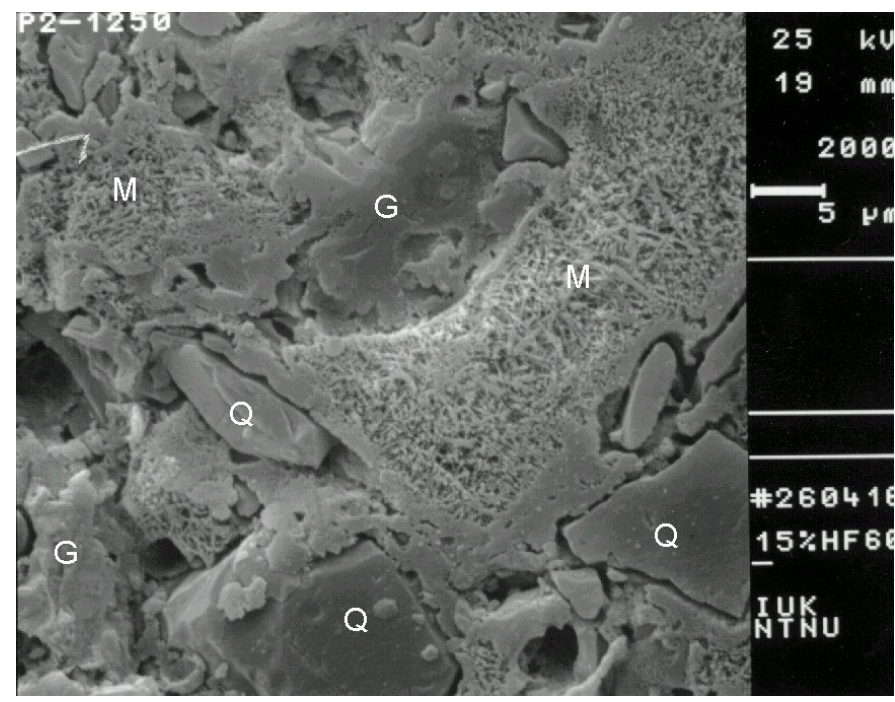

Figure 4. Scanning electron micrographs of porcelain P2 samples fired for 8 hours at (a) $1200{ }^{\circ} \mathrm{C}$ and (b) $1250{ }^{\circ} \mathrm{C}$ showing mullite needles $(\mathrm{M})$, glass phase $(\mathrm{G})$ and residual quartz grains $(\mathrm{Q})$.

Correlation between strength and mullite content

In Part I [8] it was shown that the bulk density has a strong influence on the strength of porcelain samples. In this part the role of mullite content in the strengthening of the matrix is analysed. A presentation of the dependence of strength on mullite content is displayed in Figure 5 . 
It is obvious from these results that, both mullite content and the MOR increase in the lower temperature region of the curves, with coinciding peaks at 1200 or $1250{ }^{\circ} \mathrm{C}$ hold temperatures. Beyond the peak value both quantities show a decrease in their magnitudes. The same trend was observed in Part I [8] whereby the strength was observed to increase with bulk density. However the fact that the bulk density reached the maximum at $1200{ }^{\circ} \mathrm{C}$ for all samples [8] while in some samples the MOR continues to increase up to $1250{ }^{\circ} \mathrm{C}$ (samples P1 and P4 in Figure 5) shows that the role of mullite in body strengthening surpasses that of bulk density.

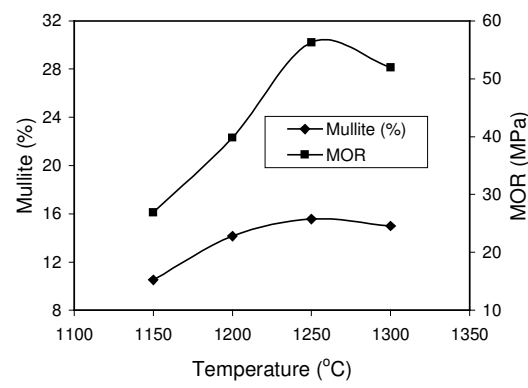

P1

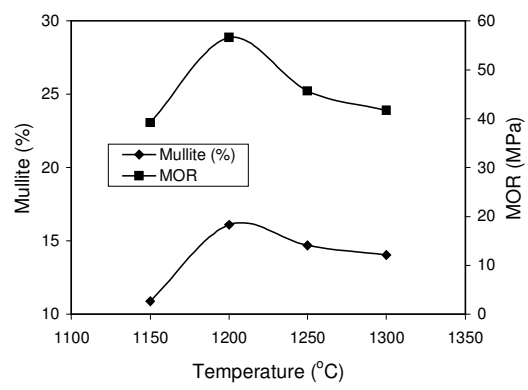

$\mathrm{P} 2$
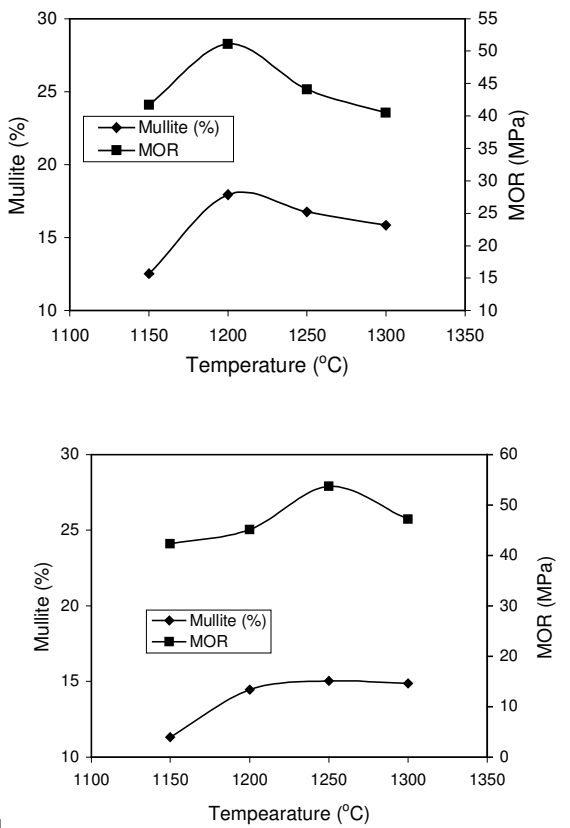

Figure 5. Variation of the modulus of rupture with the mullite content plotted against the firing temperature for porcelain $\mathrm{P}$ samples.

\section{CONCLUSION}

All mechanisms of strength development in engineering materials have one common property, i.e. to formulate a continuous matrix in the structure. In the present work an attempt has been made to make a correlation between the strength of the test samples and crystalline contents.

Quantitative determination carried out in this work has revealed that it is only mullite, quartz and the glass phase that are of significant amounts capable of influencing the matrix. There is a clear indication that the strength increases with the mullite content before the later attains a constant value. Beyond maximum value there is a reduction of strength that is explained to be due to the coarsening of the mullite needles [17]. It is observed in this work that this maximum temperature is $1250{ }^{\circ} \mathrm{C}$. The increase in mechanical strength seems to be correlated with mullite content. The internal stress theory is not seen to be significant in this work. This is due to the presence of an appreciable separation between the grains and the mullite/glass phases (Figure 4)

Bull. Chem. Soc. Ethiop. 2004, 18(1) 
which is a clear indication that the grains do not cause any stress within the matrix. Furthermore, structural flaws, at points where glass formation did not develop sufficiently to produce a strong network could act as sites of fracture initiation, and thus weakening the material.

Earlier work by Kobayashi et al. [18] has established that the mechanical strength of the commercial bodies in the quartz-feldspar-kaolin system varies in the range of approximately 6-11 kgf/mm (i.e. 58 - $107 \mathrm{MPa}$ ). They used quartz grains of size in the range of $10-30 \mu \mathrm{m}$. In the present work, porcelain materials based on Pugu kaolin have shown to have strength values ranging between $28-57 \mathrm{MPa}$. The quartz grains used have sizes up to $74 \mu \mathrm{m}$. The low strengths of the fired products originate from the structural flaws around large quartz grains, where there is a discontinuity in the three-dimensional network (Figure 4). As discussed earlier these areas will act as sites of fracture initiation causing the lowering of the flexural strengths of the material, it is therefore necessary to remove the quartz grains of large sizes, above 30 microns, in order to obtain materials of high strength. From this work it is concluded that the kaolin clay from the Pugu deposit is a suitable material for the fabrication of ceramic materials.

\section{REFERENCES}

1. Carty, W.M.; Senapati, U. J. Am. Ceram. Soc. 1998, 81, 3.

2. Sane, S.C.; Cook, R.L. J. Am. Ceram. Soc. 1951, 34, 145.

3. Mattyasovszky-Zsolnay, L. J. Am. Ceram. Soc. 1957, 40, 299.

4. Kreimer, D.B.; Chistyakova, T.I. Glass Ceram. 1989, 46, 489.

5. Waye, B.E.; Ashley, M.; Gibson, B.; Hales, B.; James, G. Trans. Brit. Ceram. Soc. 1963, 62, 421.

6. Yamamoto, N. NGK Review 1962, 25, 17.

7. Maity, S.; Sarkar, B.K. Interceram. 1995, 44, 318.

8. Akwilapo, L.D.; Wiik, K. Bull. Chem. Soc. Ethiop. 2003, 17, 147.

9. Link Analytical Co. Chemical Analysis of Portland Cement, Raw mix and Related Raw Materials by EDXRF, Application Note, Link Analytical, High Wycombe, Bucks; 1997.

10. Musikant, S. What Every Engineer Should Know About Ceramic, Marcel Dekker: New York; 1991.

11. Levin, E.M.; Robbins, C.R.; McMurdie, H.F. Phase Diagrams for Ceramics, Reser, M.K. (Ed.); American Ceramic Society: Columbus, Ohio; 1964.

12. Funk, J.E.; Dinger, D.R. Predictive Process Control of Crowded Partculate Suspensions Applied to Ceramic Manufacturing, Kluwer Academic Publishers: Boston; 1994.

13. Cullity, B.D. Elements of X-Ray Diffraction, 2nd ed., Addison Wesley: Reading, Massachusetts; 1978.

14. Alexander, L.; Klug, H.P. Anal. Chem. 1948, 20, 886.

15. Johnson, S.M.; Pask, J.A. Am. Ceram. Soc. Bull. 1982, 61, 838.

16. Schroeder, J.E.; Guertin, J.P. Extremely High Strength Porcelain, McGraw-Edison Co. 17. Franksville, WI, 722, Research Project 427-1; April 1978.

17. Maity, S.; Sarkar, B.K. J. Eur. Ceram. Soc. 1996, 16, 1083.

18. Kobayashi, Y.; Ohira, O.; Ohashi, Y.; Katoh, E. J. Ceram. Soc. Jpn. 1991, 99, 495. 